\title{
HIGHER EDUCATION INSTITUTIONS' ORGANIZATIONAL STRUCTURES IN THE CONTEXT OF MANAGEMENT BY OBJECTIVES APPROACH
}

Dita Stefenhagena ${ }^{1,}$ Dr.sc.admin., Voldemars Bariss ${ }^{2,}$ Dr.phil. assoc. professor ${ }^{1}$ Latvian Trade Union of Education and Science Employees (LIZDA), SIA "Alberta koledza"; ${ }^{2}$ Latvia University of Life Sciences and Technologies (LLU)

\begin{abstract}
There are 47 higher education institutions (HEIs) in Latvia (IZM data, 2018), but the number of students every year becomes smaller. That leads to a necessity for consolidation of HEIs and optimization of their administrative structures. At the same time, higher education (HE) normative regulations apply new tasks and responsibilities for HEIs (e.g., the development of internal quality management systems, strategy management,- etc.) which require new administrative functions, structures and additional resources. These controversial circumstances aren't supportive for HEIs' institutional management to develop processes in accordance with management by objectives (MBO) approach and to reach goals and objectives in HE studies and research. The aim of the paper is to research problems which interfere the development of organizational structures in accordance with the MBO approach in HEIs in Latvia. The authors have used the results from the HEIs' survey (DU, LLU, LU, LiepU, RSU, RTU) and interviews (ViA, VeA, JVLMA, BA, RPIVA (since 2017 consolidated with LU), LSPA) in Latvia. The paper is developed using research of the promotional thesis "Implementation of management by objectives approaches at higher education institutions in Latvia" (Stefenhagena, 2017). The research of the promotional thesis was carried out from 2010 to 2017. The conclusion of the paper is that HEIs' organizational structures are fragmented, and there is a tendency of duplicating administrative functions and duties. In order to apply MBO approach, a more sufficient analysis of administrative functions, processes, goals and objectives have to be carried out. Horizontal instead of vertical (hierarchic) cooperation among administrative units is encouraged.
\end{abstract}

Key words: higher education institution (HEIs), organizational structures, management by objectives approach JEL code: 123

\section{Introduction}

The paper highlights the problem of developing effective and goal oriented administrative structures at HEIs institutional management. The state budget allocation criteria for public HEIs are becoming more quality and result oriented. New functions and processes what have to be integrated into HEIs' institutional structure appear year by year. There are several contradictions in the policy of HEIs administrative functions and objectives that have to be implemented. For example, HEIs administrative units/functions have to be consolidated (in accordance with the state policy, the State Audit report, 2017), but the tasks and objectives which are applied by external normative regulations for public HEIs are growing.

The research object of the paper is public HEIs in Latvia. The aim of the paper is to research problems which interfere the development of organizational structures in accordance with the MBO approach in HEIs in Latvia. In order to follow the research aim, the following tasks were carried out: 1. to research theoretical concepts of MBO approach and organizational structures in public institutions; 2. to describe the current situation and problems with MBO oriented organizational structures in HEIs in Latvia; 3. to come up with conclusions. The research methods: analysis of scientific literature, the survey and interviews conducted at public HEIs. Different level managers (survey), administrative directors and quality managers (interviews) are representatives of HEIs executive power or institutional management, and changes of organizational structures can be initiated by them.

The research results from the survey and interviews indicated that different level managers are of opinion that administrative functions in HEIs aren't balanced and they are duplicated, HEIs' organizational structures are too hierarchic preventing cooperation in execution of tasks and 
processes among administrative units. Implementation of recommendations on changes in structural units of internal audit has to be not only documented but also carried out in practice. The authors' research results in some ways correspond with the results presented by the State Audit report at the end of 2017.

\section{Research results and discussion}

\section{MBO approach and its application in HEIs' management}

The MBO approach is a popular one and widely used in management science. The origin of the theory comes from the classical management theories (H. Fayol, F.W. Moonley, L. Urwick), which "formed theoretical basis for rational planning and control in industrial manufacturing" (Morgan G., 1997:18). The MBO approach was developed further by P. Drucker in his 1954 book "The Practice of Management". P Drucker reflected the classical management scheme of organization: organizations utilize human, material, financial, information and other resources, lead the recourses to a concrete objective, in order to achieve a value added result in a form of a product or service (Understanding the Theory, 2007).

There are indications in scientific sources that the MBO principles are applied to HEIs' management in the context of public management theory - the New Public Management. Italian authors T. Agasisti and G. Catalano in their research on contemporary tendencies of HEIs' management have developed a link between the New Public Management theory and the MBO approach, on the one hand, and HEIs' management processes in Europe, on the other hand: „improvements in higher education institutions' management is a part of a broader management process the aim of which is to improve efficiency and quality of the public sector" (Agasisti T., 2006:13). It has been emphasized that reforms of a better management and governance of higher education institutions are developed from the New Public Management and MBO ideas of application of new management approaches (Stensaker B. et al, 2007).

The MBO approach in every public institution, including HEI, is closely connected with the organizational structure. The organizational structure shows what are the functions and processes implemented in accordance with institution's goals and objectives. One of the most popular models of structures is the functional model of organizational structure developed by H. Mintzberg (1998).

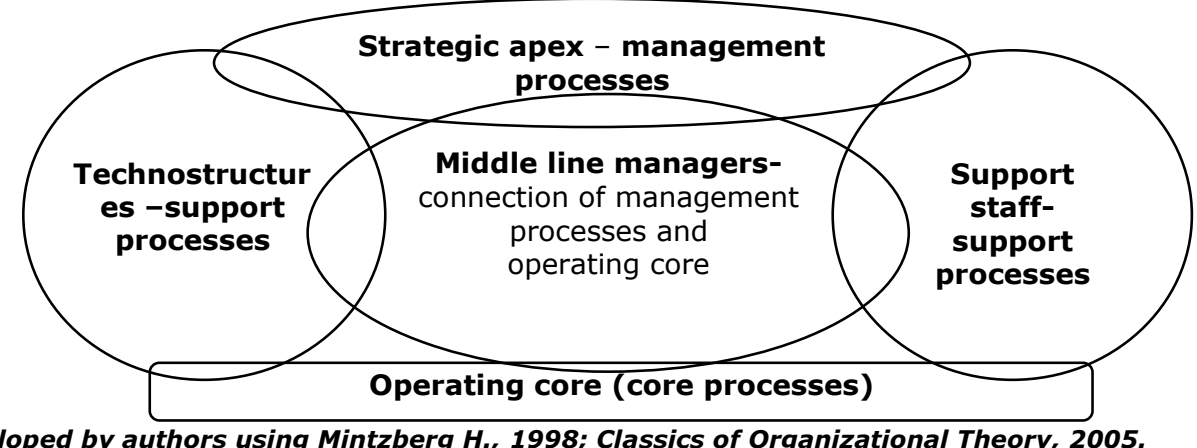

Source: developed by authors using Mintzberg H., 1998; Classics of Organizational Theory, 2005.

Fig. 1. Organizational Structure in Accordance with Functional Parts and Processes.

The core processes and functions are those which are connected with organization's mission and strategy. Support processes and functions are those which provide assistance to core functions. There are five functional parts of organizational structure - strategic core which consists of management functions, operating core - the basic functions and processes, the middle line managers - connection of management functions with the operating core, and the support 
functions - in order to implement the core processes, organizations obtain technostructures and support staff (Mintzberg H., 1998; Classics of Organizational, 2005.) (Fig.1.).

From the theoretical research it has to be stated that every public institution, including HEI, has its organizational structure which indicates tree types of processes and functions: the core processes and functions, management processes and functions and support processes and functions. Processes and functions are formed in structural units and represent organizational structure. The theoretical concepts indicate that public organizations, including HEI, organizational structure is supposed to be effective (well functioning) and goal oriented (MBO approach). Public management sources (Daft R.,2010; Governance in the 21th Century, 2003) point out that traditional hierarchic or functional organizational model isn't effective enough to operate nowadays in a dynamic and demanding higher education environment. In a hierarchic structure, higher level managers can't make decisions and solve problems as it is required by quickly changing social and economic environment. Necessity for new, flexible, flat matrix structures, horizontal cooperation, and higher level managers' direct cooperation with specialists is increasing.

\section{Description of problems in current organizational structures of HEIs}

Introduction and application of the MBO approach is closely connected with changes of organizational structure of HEIs. As mention in previous analysis, responsibilities and tasks, which have to be executed by HEIs' administration, are increasing.

Development of HEI's organizational structure is influenced by conditions of HEI's autonomy, the decision making power and the executive power. Organizational structure is determined by normative regulations, collegial decisions, as well as specific goals and objectives of each HEI.

The Law on Higher Education Institutions determines:

1) organizational structure of HEI is developed, reorganized and liquidated by the HEIs constitution;

2) tasks, functions, responsibilities and rights of structural units are determined by the structural units' regulations which are approved by the senate (The Law on HEIs, edition 01.01.2018.).

On the one hand, as regulated by the Law on Higher Education Institutions, HEIs are autonomous institutions which decide on their organizational structures, but on the other hand, more objectives and tasks are applied to HEIs by external normative regulations, and that requires additional administrative positions and structural units. The organizational structure of HEI can be divided into the decision making power (governance) and the executive power (management). The executive power in cooperation with administrative units (heads of administrative units, and other administrative personnel) are directly responsible for modernization of HEI's management, for the development of functions and organizational structure in accordance with goals, objectives and tasks. Changes in organizational structure - administrative units and functions, have to be made in accordance with changes in goals, objectives and tasks. For example, the practical implementation of internal quality management systems (required by the Law on HEIs, article 5, point 2) asks for new competences and functions. HEIs have to consistently foresee what structural changes are necessary in order to implement all tasks and requirements of institutional management.

The research of the higher education consulting enterprise "Dynamic University" indicates that the majority of HEIs have pointed out that they have hired a quality management specialist for ensuring implementation of quality management. Much less HEIs have indicated that they have 
responsibility of quality management implementation at each structural level or unit (AII ieksejas kvalitates nodrosinasanas, 2013).

Based on research of HEIs' organizational structures and documents, the "Dynamic University" research results, the authors consider that quality management and internal quality assurance systems are more centralized than decentralized in HEIs in Latvia. Quality management is implemented at the institutional level by executive staff in cooperation with personnel of the administrative units. The position of a quality manager/specialist is subordinated to HEI's rector or vice-rector/administrative director. That may lead to a situation when MBO approach is implemented in a centralized manner - at the institutional management level, without decentralization to other structural levels of HEI. Similar conclusions, emphasizing the necessity to acknowledge the essence and goals of the MBO approach (quality management) at all structural levels of HEI, have been formulated by the "Dynamic University" research - "it is important to ensure that not only one structural unit or specialist is responsible for implementation of quality management. Information and facts have to be transparent and spread at all levels of HEI....Personnel may significantly impact the implementation of necessary changes in practice, thus, it has to be ensured that personnel is informed about the aims and benefits of quality management. The benefits of internal quality assurance and quality management system have to be clear. Low motivation of using quality management system is usually connected with insufficient ability to see the added value of quality management" (AII ieksejas kvalitates nodrosinasanas, 2013:16). The responsibility to implement quality management not only at the central administrative level (centralized quality management) but also at other structural levels (faculties, institutes, departments - decentralized quality management) shows the necessity for even more administrative positions than currently exist in HEIs organizational structures. Also, it has to be stated that considering the limited resources of smaller HEIs (number of students less than 1000, e.g.,- ViA, VeA, JVLMA) it might be problematic to ensure the responsibilities of MBO approach at the central and decentralised levels.

The authors consider that HEIs have to assess their resources and possibility to introduce positions of quality management/strategy management specialists because it is important that MBO approach is used at all structural levels of HEI. It is possible to combine positions, e.g., the responsibilities of quality management can be assigned to faculty deans, heads of departments or other administrative personnel.

HEIs' organizational structures are assessed also by other controlling institutions. At the end of 2017 the State Audit Office of the Republic of Latvia developed the audit report on efficiency of higher education financing system in Latvia. The conclusions are applied also to the organizational structures of public HEIs. Some of these conclusions are:

- HEI's governance and management systems are not effective, and financial and material resources are not used in a rational and effective manner;

- Organizational structures are fragmented - a large number of bigger structures consist of a significant number of smaller structures with a small number of employees;

- There is a tendency of duplicating administrative functions and duties - e.g., an organizational structure is formed to implement concrete objectives, but tasks to reach the objective are implemented by other structural units;

- HEIs organizational structures are not transparent. It isn't possible to get information on the number of administrative personnel in all organizational structures; 
- The State Audit concludes that HEIs organizational structures are large by size and fragmented; they aren't optimized for saving administrative expenses. (Vai augstakas izglitibas finansesanas sistema, 2017).

In smaller structural units, there is a tendency to employ one to two employees. The total number of academic personnel against the number of administrative personnel was compared. Although there is a tendency to decrease the number of administrative personnel, the ratio between academic and administrative personnel is still high: in 2013/2014 it was $93 \%$, but in 2016/2017 - 75 \% (Vai augstakas izglitibas finansesanas sistema, 2017).

Based on the State Audit results, the following recommendation was developed in order to improve HEIs' organizational structures: the Ministry of Education and Science has to develop activities for HEIs to review and optimize their structures. HEIs structure has to be developed with less fragmentation and with optimized administrative costs.

\section{Results from the survey and interviews}

The authors conducted a survey of different level managers at six HEIs (DU, LLU, LU, LiepU, RSU, RTU) in Latvia. The authors' task was to find out opinion of different level managers on achievements and problems of implementation of MBO approach at their institutions and to clarify the division of administrative functions of HEIs' management.

The survey contained 20 questions, 13 questions were structured as basic questions and 7 questions referred to respondents' demographical data. Questions contained rating scale from 1 to 10, where 1 - "completely disagree", "not important" "definitely no", 10 - "completely agree", "very important", "definitely yes". The data was summarized and analysed in 3 groups: the 1st group (responses from 1 to 4) summarizes an opinion which is "definitely disagree, disagree, rather disagree"; the 2nd group (responses from 5 to 6) - lacking opinion or missing information on the issue. The 3rd group (responses from 7 to 10) summarizes an opinion which is "rather agree, agree, completely agree".

The general set $(\mathrm{N})$ - different level managers was 950. Responses were given by 209 different level managers ( $22 \%$ of the general set) which was valid for the representation of a sample.

$48 \%$ of respondents were of opinion that functions of administrative personnel are clearly defined and don't duplicate, $23 \%$ of respondents didn't agree to this statement, but $29 \%$ respondents didn't have opinion on the issue. The majority of respondents (44\%) were of opinion that the workload of administrative personnel is not balanced, but $24 \%$ of respondents didn't have opinion on this issue (Fig.2.). 


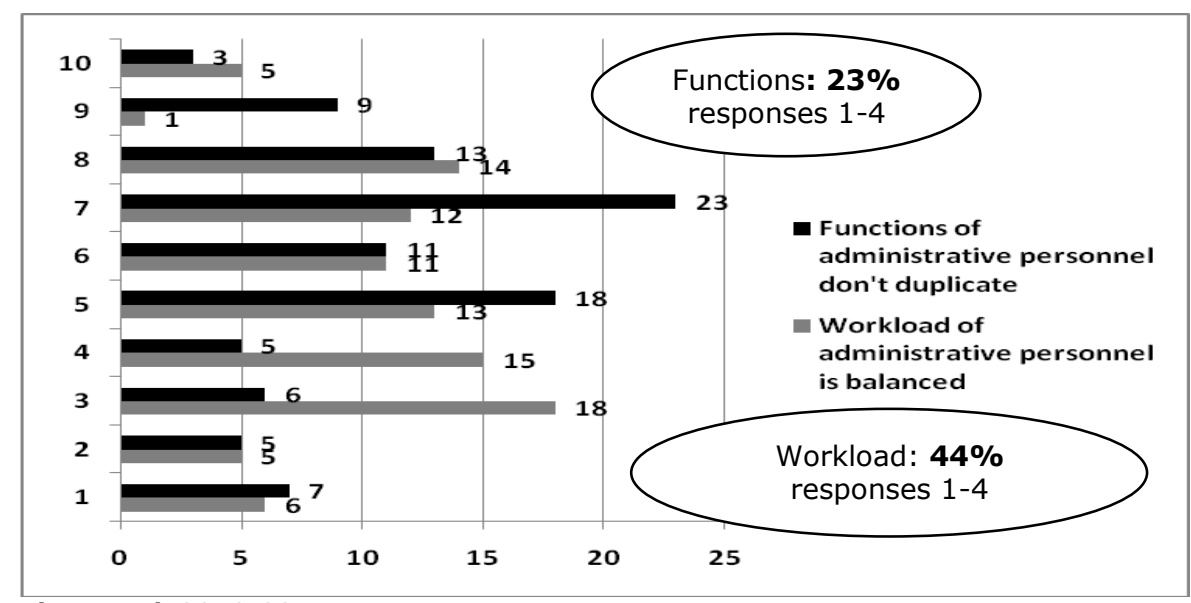

Source: authors' research 2010-2017

Fig. 2. Respondents' opinion ( $\%$ ) on statements „Functions of administrative personnel don't duplicate" and "Workload of administrative personnel is balanced", $n=204$ (1- completely disagree; 10-completely agree).

Based on high proportion of responses - "don't have opinion", or "missing information on the issue", an assumption might be developed that different level managers are missing information about functions, assessment, training and career possibilities of administrative personnel. Information and communication problems among administrative heads/employees, executives and other managers exist. This may lead to problems of horizontal cooperation between administrative units and executives in carrying out processes and tasks.

In order to supplement and prove the survey results, expert interviews were organized at six HEIs (JVLMA, LSPA, RPIVA, VeA, ViA, BA, RPIVA) in Latvia. Administrative directors and quality managers are expertized on MBO approach in HEIs. They are responsible for implementation of quality management, strategy management and other management approaches. Interviews were conducted according to the following research topics: the management of structures and functions; optimization of administrative structures in accordance with changes in goals and objectives; assessment and evaluation of functions of administrative units and positions; how functions support goals and objectives, are they balanced. Administrative directors and quality managers expressed their opinion concentrating on the questions: are administrative directors and quality managers aware that changes in structural organization are necessary? Why the changes are necessary? What are the results of optimizing HEIs' administrative structures?

The results from the interviews with indicated that HEIs' organizational structures are too hierarchic which is considered as a preventing factor for cooperation among administrative units in coordinating tasks within processes. Administrative functions are organized in processes which consist of tasks. Every task or function has to be executed in accordance with the planned outcomes, and it has to be accomplished in certain deadlines. If there is limited cooperation among structural units, execution of tasks becomes slow and ineffective. This was justified by the following quotations:

${ }_{-}$HEIs have hierarchic culture, which is a preventing factor for effective management work, implementation of management by objectives approaches. We try to introduce more horizontal than vertical cooperation among structures"; - "The vertical communication and coordination have to be more supplemented by horizontal cooperation in order to sufficiently use quality management processes."; - „It is supportive, if there is not a strict hierarchy - tasks within processes have to be executed in accordance to its meaning and by cooperating". 
The respondents were of opinion that objectives of internal audit aren't always explained to administrative personnel, and internal auditing of structural units is perceived as an extra administrative burden. Although in some cases the results of internal auditing were evaluated as useful and necessary to make optimization of administrative structures, the respondents were of opinion that the results of internal auditing aren't carried out in practice. HEIs institutional environment in many cases were assessed as slow and resistant to change. The analysed results were justified by the following quotations:

-"Organizational structures are changed in accordance with the recommendations from the internal audit. But HEI's institutional environment is slow and conservative. Changes happen but in a longer period of time"; -"HEI's administrative structures will become flatter, smaller in the future"; -"There needs to be improvement in the work of internal audit. Activities of the internal audit have to be qualitative and well grounded - it shouldn't be as an extra burden for structural units. It has to be explained to all structural units - what will be audited and how the results of the audit will be used".

Results from the interviews as well as results from the survey indicated that in order to improve efficiency of administrative processes, there needs to be cooperation between administrative units and clear division of functions. Duplication of administrative functions in administrative units is a common situation in large institutions, including HEIs: for the personnel to cooperate, functions shouldn't duplicate. Such organizational structure I see as a key element for the HEI to implement its goals and objectives" (Authors' research 2010-2017).

As a conclusion from the results of the survey and interviews, it might be indicated that by organizing HEIs' institutional management processes in accordance with implementation of MBO approach, it is possible to reach more dynamic and effective management of core and support processes and moving to improved performance results.

The major problems of implementation of MBO approach are connected with insufficient analysis of administrative functions and slow reorganization followed by recommendations of internal audit. Execution of tasks and processes are more in accordance with the functional management structure than horizontal cooperation. The survey results indicated that almost $1 / 4$ of the respondents $(23 \%)$ were of opinion that administrative functions are duplicating, and $29 \%$ respondents didn't have opinion on the issue, what might indicate that different level managers aren't sufficiently informed about administrative processes in HEIs.

\section{Conclusions}

In order to introduce and implement MBO approach at institutional management, the majority of HEIs have optimized their organizational structures by integrating the functions and processes of strategic, quality and performance management. Also it has to be stated that HEIs' organizational structures are organized in accordance with theoretical concepts (Mintzberg, 1998), organizational structures are divided into the core, management and supportive processes and functions.

The following problems prevent to develop HEIs' organizational structures according to MBO approach:

1) The functions of administrative unites aren't sufficiently analysed and assessed (e.g., implementation of recommendations of functional audits), and changes of organizational structure and functions are slow and resistant to change. That is considered the obstacle of implementation of MBO approach - strategic and quality management at HEIs in Latvia. 
2) Strictly organized vertical hierarchic structure is considered an obstacle for implementation of MBO approach. Hierarchic structure doesn't promote horizontal cooperation among structures and functions, and the execution of administrative tasks becomes slow an ineffective.

3) Smaller HEIs (number of students less than 1000, e.g. VeA, ViA, JVLMA) are limited in administrative resources, and positions of specialists/managers of quality and strategy management aren't introduced.

4) Organizational structures of HEIs in many cases are fragmented - a large number of bigger structures consist of a significant number of smaller structures with a small number of employees.

5) There is a tendency of duplicating administrative functions and duties -an organizational structure is formed to implement concrete objectives, but tasks to reach the objective are implemented by other structural units.

6) The workload of administrative functions isn't balanced among administrative positions.

\section{Recommendations}

1) Development of a HEI's structure as a matrix type organization, using more horizontal cooperation, principles of project and team work, in order to improve process management and achievement of outcomes and performance results, would be helpful to ensure MBO approach.

2) Activities for HEIs to review and optimize their structures have to be developed. HEIs structure has to be developed with less fragmentation and with optimized administrative costs.

3) Necessity for new and flexible administrative structures, promoting horizontal cooperation, and higher level managers' direct cooperation with specialists, is increasing at HEIs institutional management.

\section{Bibliography}

1. Augstakas izglitibas iestazu kvalitates nodrosinasanas sistemu efektivitates novertesana, gala zinojums. IZM sadarbiba ar SIA Dynamic University (2013), 27 Ipp.

2. Agasisti T., Catalano G. (2006). Governance Models of University Systems-Towards Quasi-Markets? Tendencies and Perspectives: a European Comparison, Journal of Higher Education Policy and Management, Vol. 28, No 3, November 2006, pp. 245-262.

3. Classics of Organization Theory. 6th edition (2005). Edit. Shafritz J.M., Ott J.S., Yang Y.S., Thomson W., p.544.

4. Daft R. (2010). New Era of Management. 9th edition. South Western Cengage Learning, p. 668

5. Governance in the 21th Century: Revitalizing the Public Service (2003). Editors: B.G. Peter, D. J. Savoie. Montreal: Canadian Centre for Management Development: McGill - Queen's University, p.438.

6. IZM data on Higher Education Institutions (2018). Retrieved: http://www.izm.gov.lv/Iv/izglitiba/augstakaizglitiba/augstakas-izglitibas-iestades. Access: 01.02.2018.

7. Mintzberg H. (1998). The Structure of Organizations: Review of Structure in Fives: Designing Effective Organizations, p.235

8. Morgan G. (1997). Images of Organizations. Sage Publications Inc., p. 485.

9. Stensaker B., Enders J., Boer H.F. (2007). Comparative Analysis. Final report of the project: the Extent and Impact of Governance Reform across Europe. European Commission, Brussels, pp. 123-233

10. Stefenhagena D. (2017). Uz rezultatu orientetu vadisanas pieeju izmantosana augstskolas Latvija. Promocijas darbs, Latvijas Universitate. Retrieved: https://dspace.lu.Iv/dspace/bitstream/handle/7/37280/298-61697-

Stefenhagena_Dita_ds10120.pdf?sequence=1\&isAllowed=y. Access: 11.03.2018.

11. The Law on Higher Education Institutions (1995). Edition 01.01.2018. Retrieved: https://likumi.Iv/doc.php?id=37967. Access: 01.02.2018.

12. Vai augstakas izglitibas finansesanas sistema ir efektiva? (2017). LR Valsts kontroles revizijas zinojums, pp. 137 